\title{
In vitro and In vivo Evaluation of Flavonoids from Heliotropium ellipticum Exudate for Antioxidant, Antineoplastic and Cytotoxic Activities II
}

\author{
B. SINGH ${ }^{*}$, P. M. SAHU ${ }^{1}$ AND R. A. SHARMA ${ }^{1}$
}

Institute of Biotechnology, Amity University Rajasthan, Jaipur-303 002, ${ }^{1}$ Medicinal Plants Research Laboratory, Department of Botany, University of Rajasthan, Jaipur-302 004, India

\section{Singh, et al.: Antioxidant and Anticancer Evaluations of Heliotropium ellipticum}

\begin{abstract}
Flavonoids are a large group of plant secondary metabolites that occur in various types of fruits and vegetable crops. The present study attempted to isolate and test flavonoids from the Heliotropium ellipticum exudate for antioxidant, antineoplastic and cytotoxic effects. Results obtained revealed that chrysin demonstrated higher DPPH scavenging $(297.21 \pm 0.36 \%)$, reducing power $(428.21 \pm 0.23 \%)$, superoxide anion scavenging $(283.59 \pm 0.39 \%)$ and metal chelating $(459.52 \pm 0.11 \%)$ activities. Chrysin showed greater antioxidant activity in comparison to the standard ascorbic acid. Similarly, it also exhibited high activity against sarcoma 180 $(81.90 \%)$ and Chinese hamster V79 $(37.2 \pm 0.67 \%)$ cells at different tested concentrations. Results obtained suggested that chrysin could be used as a potent antioxidant, antineoplastic and cytotoxic agent.
\end{abstract}

Key words: Heliotropium ellipticum, antioxidant, antineoplastic and cytotoxic activities, flavonoids, Sarcoma 180, Chinese hamster V79 cells

Most species of Heliotropium genus inhabit arid zones of the world and are bestowed with the ability to withstand adverse environmental conditions. Due to continuous exposure to extreme conditions, these species secrete resinous exudates from trichomes situated on the aerial parts of plants ${ }^{[1]}$. These aerial parts of $H$. ellipticum were recommended as remedy for ulcers, headache, ear ache, scorpion stings, boils, snake bites and mad dog bites ${ }^{[2-4]}$. Reports showed that phytochemicals of resinous exudates possessed antioxidant, antimicrobial, and antiinflammatory activities ${ }^{[5-8]}$. During the cellular metabolic processes free radicals are formed. These free radicals are important for cell signaling, apoptosis, ion transportation and gene expression. However, excess amount of free radicals lead to damaged nucleic acids and fatty acid double bonds, which result in increased risk of diseases ${ }^{[9]}$. Reducing power assay is normally based on capacity to donate an electron by flavonoids ${ }^{[10]}$. Literature reported that reducing power and antioxidant activities of flavonoids are positively correlated to each other ${ }^{[11]}$. Excess concentration of superoxide anion radicals is also harmful to cell metabolism because being precursors of reactive oxygen species (ROS) ${ }^{[12]}$. Several researchers have

*Address for correspondence E-mail: bharatsingh217@gmail.com

November-December 2017 also investigated the metal chelating actions of flavonoids ${ }^{[13]}$. Although several synthetic antioxidant drugs are commercially available, researchers focus more on antioxidant activity of natural products since these are believed to be safer ${ }^{[14]}$.

Cancer is a major health concern of human population of the world. Several anticancer drugs are very much used in clinical practices ${ }^{[15]}$. Due to the side effects of cytotoxic drugs, scientists are now searching alternative options of modification in the treatment of cancers ${ }^{[16]}$. In recent years, lot of efforts have been made to discover novel natural products from plants having similarity with anticancer synthetic molecules to check the growth of cancer in human population ${ }^{[17]}$. As per available reports, plant flavonoids were considered as potent antioxidant, anticancer and cytotoxic agents. Therefore, we evaluated the antioxidant, antineoplastic

This is an open access article distributed under the terms of the Creative Commons Attribution-NonCommercial-ShareAlike 3.0 License, which allows others to remix, tweak, and build upon the work non-commercially, as long as the author is credited and the new creations are licensed under the identical terms

Accepted 27 September 2017

Revised 29 March 2017

Received 08 November 2016

Indian J Pharm Sci 2017;79(6):939-947 
and cytotoxic activities of isolated flavonoids in select experimental models.

\section{MATERIALS AND METHODS}

The plant material was collected (March, 2013) from the fields of Agricultural Research Station, Durgapura, Jaipur and the plant identity was confirmed in the Department of Botany, University of Rajasthan, Jaipur, India (herbarium sheet no. RUBL-20494). Melting points (MP) of isolated flavonoids were determined on the capillary Toshniwal melting point apparatus. The following instruments were used for spectral studies of isolated flavonoids: infrared (IR), NicoletAvatar 330 Fourier-transform infrared spectroscopy (FTIR); mass spectroscopy (MS), Hewlett Packard HP 5930 A; nuclear magnetic resonance (NMR), Bruker AM 400 system at 400, 100 and $50 \mathrm{MHz}$. For column chromatographic studies, silica gel 60 (230-400 mesh; Merck) was used. The isolated compounds were purified by preparative thin layer chromatography (PTLC; silica gel G; Merck).

\section{Extraction and characterization:}

Fresh plant material $(2.5 \mathrm{~kg})$ was immersed in dichloromethane (2.5 1) for $30 \mathrm{~s}$ and then crude fraction was dried in vacuo (18.278 g). The crude dichloro methane fraction was subjected column chromatographic studies. From column chromatography, total ten fractions (1-10) were separated. Total five flavonoids were isolated and characterized from the separated fractions. The purification of compounds was performed by PTLC $(20 \times 20 \mathrm{~cm}$ diameter glass plates and wet thickness$0.5 \mathrm{~mm})$.

\section{3-O-methylgalangin and naringenin-4,7-dimethyl ether:}

Fractions 1 and 2 were mixed together $(3.766 \mathrm{~g})$ and the compound was purified by PTLC. The solvent system used as $\mathrm{CHCl}_{3}: \mathrm{MeOH}(8.0: 2.0, \mathrm{v} / \mathrm{v}), \mathrm{R}_{\mathrm{f}} \sim 0.43$, vanillin reagent used for the detection of compound on TLC, yielded to compound 3-O-methylgalangin, MP $184-186^{\circ}, \mathrm{C}_{16} \mathrm{H}_{12} \mathrm{O}_{5}$, qualitative identity confirmed by Shinoda test. Fractions 3 and 4 were combined (3.435 g) and the compound purified by PTLC. Solvent system - $\mathrm{CHCl}_{3}: \mathrm{MeOH}(1.0: 1.0, \mathrm{v} / \mathrm{v}), \mathrm{R}_{\mathrm{f}} \sim 0.28$, spraying reagent - vanillin reagent, Shinoda test used for qualitative determination, yielded to naringenin-4, 7-dimethyl ether, MP $163-165^{\circ}, \mathrm{C}_{17} \mathrm{H}_{16} \mathrm{O}_{5}$. The identity of isolated compounds was confirmed with the physical and spectral data of reference compounds reported in literature ${ }^{[18,5,19]}$.

\section{Chrysin and luteolin:}

Fractions 5-8 were pooled $(7.621 \mathrm{~g})$ and the compounds purified by means of PTLC. Solvent system - $\mathrm{CHCl}_{3}: \mathrm{MeOH}$ :formic acid (8.4:1.1:0.5, v/v), $\mathrm{R}_{\mathrm{f}} \sim 0.30$, MP $280-282^{\circ}, \mathrm{C}_{15} \mathrm{H}_{10} \mathrm{O}_{4}$, a yellow powder, qualitative test positive to Naturstoff reagent A reagent, the compound yielded to chrysin. Similarly, the preparative TLC was further used for the purification of another compound. Solvent system - EtOAc:formic acid:AcOH: $\mathrm{H}_{2} \mathrm{O}(100: 10: 10: 20, \mathrm{v} / \mathrm{v}), \mathrm{R}_{\mathrm{f}} \sim 0.28$, yielded compound to luteolin, MP 313-314, $\mathrm{C}_{15} \mathrm{H}_{10} \mathrm{O}_{6}$, yellow crystals, tested positive to Naturstoff reagent A. Both isolated flavonoids were characterized by spectral analysis and data compared with standard compounds ${ }^{[20,21]}$.

\section{Sakuranetin:}

Fractions 9 and 10 pooled together $(3.987 \mathrm{~g})$ and used for the purification of compound. Toluene:formic acid:ethyl formate $(5.5: 0.9: 4.2, \mathrm{v} / \mathrm{v})$ used as solvent system, detected by vanillin reagent, yellow needles, $\mathrm{C}_{16} \mathrm{H}_{14} \mathrm{O}_{5}$, MP $164-166^{\circ}$, qualitative test negative to $\mathrm{Mg}-\mathrm{HCl}$ reagent, $\mathrm{R}_{\mathrm{f}} 0.47$, yielded to sakuranetin. The IR, NMR, MS data of isolated compound was in agreement with standard compound ${ }^{[22]}$.

\section{1,1-diphenyl-2-picrylhydrazyl (DPPH) scavenging assay:}

For the evaluation of the DPPH scavenging activity of test samples (dichloromethane fraction, isolated compounds and ascorbic acid), Yokozawa et al. ${ }^{[23]}$ protocol was used. The three concentrations $(10,20$, $30 \mu \mathrm{M})$ of test samples were transferred to the DPPH solution $(0.5 \mathrm{ml}$ in $\mathrm{MeOH}, 150 \mu \mathrm{M})$ and agitated continuously for $1 \mathrm{~h}$ at room temperature. After proper mixing, the readings of reaction mixtures were taken at $517 \mathrm{~nm}$ on UV spectrophotometer (Schimadzu UV/ Vis 1700). For this study, $\mathrm{MeOH}$ was used as blank while ascorbic acid tested as positive control. Higher radical scavenging activity was indicated by lower absorbance of reaction mixtures. Inhibition rate (\%) of DPPH activity was determined as follows, inhibition rate $(\%)=$ absorbance $_{\text {control }}-$ absorbance $_{\text {test }} /$ absorbance $_{\text {control }} \times 100$.

\section{Reducing power assay:}

Three concentrations $(10,20$ and $30 \mu \mathrm{M})$ of experimental test samples were mixed with phosphate buffer $(\mathrm{pH}$ 
6.8) and potassium ferrocyanide and the mixture of samples agitated continuously for proper mixing at $50^{\circ}$ for $20 \mathrm{~min}^{[24]}$. Later, 2-3 drops of trichloroacetic acid was mixed to the reaction samples and centrifuged at $1000 \mathrm{~g}$ for $15 \mathrm{~min}$. After centrifuging properly, the upper layer of samples was collected and distilled water $(2.5 \mathrm{ml})$ as well as $\mathrm{FeCl}_{3}(0.5 \mathrm{ml})$ added to the reaction samples. After $15 \mathrm{~min}$, the absorbance of test samples was recorded at $700 \mathrm{~nm}$ on UV spectrophotometer using phosphate buffer as blank. The inhibition rate $(\%)$ of reducing power was calculated as follows, inhibition rate $(\%)=$ absorbance $_{\text {control }}-$ absorbance $_{\text {test }} /$ absorbance $_{\text {control }} \times 100$.

\section{Determination of superoxide anion scavenging activity:}

Nitroblue tetrazolium (NBT) reduction method was used for the assessment of superoxide anion scavenging assay ${ }^{[25]}$. The superoxide radicals were formed in phenazine methosulfate-nicotinamide adenine dinucleotide system oxidizing by NAD. The test samples were transferred to the mixture of freshly prepared superoxide radicals and the phenazine methosulfate $(1.0 \mathrm{ml} ; 100 \mu \mathrm{M})$. The reaction mixture of test samples were incubated at room temperature for $10 \mathrm{~min}$ and then absorbance recorded at $560 \mathrm{~nm}$ against blank. Decline in absorbance of the reaction mixture indicates rise in activity. The inhibition rate (\%) of activity was calculated as follows, inhibition rate $(\%)=$ absorbance $_{\text {control }}-$ absorbance $_{\text {test }} /$ absorbance $_{\text {control }} \times 100$.

\section{Determination of metal chelating scavenging activity:}

The test samples were added separately to the 3.7 $\mathrm{ml}$ of $\mathrm{MeOH}$ and $0.1 \mathrm{ml}$ of $2.0 \mu \mathrm{M}$ ferrous chloride solution ${ }^{[26]}$. The test solutions were agitated gently and $0.2 \mathrm{ml}$ of $5.0 \mu \mathrm{M}$ ferrozine was added. The reaction mixtures of test samples were incubated for $10 \mathrm{~min}$ at room temperature. The absorbance of reaction mixtures was recorded at $562 \mathrm{~nm}$. The inhibition rate (\%) of ferrozine- $\mathrm{Fe}^{2+}$ complex formation was determined as follows, inhibition rate $(\%)=$ absorbance $_{\text {control }}-$ absorbance $_{\text {tested sample }} /$ absorbance control $\times 100$.

\section{Experimental animals:}

The ICR male albino mice (four weeks old, 30-35 g weight) were used for the assessment of antineoplastic activity. The experimental animals were kept in opentop cages with sawdust bedding (Lignocel BK/15 granulate, IPS, Ltd). The bedding was manufactured of spruce (particle size: $1.5 \times 2.5 \mathrm{~mm}^{2}$ ) and the floor of cages covered with stainless steel wire mess (mess size: $2.5-3.0 \mathrm{~mm}^{2}$ ). Two animals were kept in one cage and total forty-two animals $(6 \times 7=42$; six animals in one group including control as well as treated groups) used for the determination of antineoplastic activity. The animals had ad libitum access to filtered tap water in drinking bottles and pelleted chow with $16 \%$ protein (irradiated 2916, Teklad Global 2016, Italy). The experimental room had controlled conditions with light (12/12 $\mathrm{h}$ photoperiod and dark period), temperature $\left(25 \pm 1^{\circ}\right)$, and relative humidity $(55-60 \%)^{[27]}$. The experimental study was approved by the Institutional Ethical Committee (F. No. 25/28/2014-CPCSEA dated on Sept 17, 2015; Registration No. 1823/PO/Re/S/15/ CPCSEA, Amity University Rajasthan, Jaipur).

\section{Assessment of antineoplastic activity:}

Packed cell volume (PCV) method is well known and was used for the determination of antineoplastic activity of test samples ${ }^{[28]}$. Sarcoma $180\left(1.0 \times 10^{-6}\right.$ cell/ $0.1 \mathrm{ml}$ ascite fluid) was implanted (i.p.) in experimental animals. The test samples were dissolved in saline solution and suspended in carboxymethyl cellulose. The mixture of test sample of dichloromethane fraction was administered (i.p.) at the dose of 25, 50, $100 \mu \mathrm{g} / \mathrm{kg} / \mathrm{d}$ and the isolated compounds (5, 10, $20 \mu \mathrm{g} / \mathrm{kg} / \mathrm{d}$ ) for $5 \mathrm{~d}$ regularly to experimental mice. Similarly, the saline solution was administered (i.p.) to the animals of control group for $5 \mathrm{~d}$. On $7^{\text {th }} \mathrm{d}$, the experimental animals were sacrificed and the tumor cells separated from ascite tumor by centrifugation $(3200 \mathrm{rpm}$ for 8-9 min). The PCV and total volume of tumor cells were determined in each case. The changes in the body weight of ascite tumor and tumor implanted were also measured on $7^{\text {th }} \mathrm{d}$. On $7^{\text {th }} \mathrm{d}$, the experimental animals were euthanized with $\mathrm{CO}_{2}$. The $\mathrm{CO}_{2}$ filled chambers were added with $25 \% \mathrm{O}_{2}$ to reduce distress caused by hypoxia. Due to heaviness, the $\mathrm{CO}_{2}$ settle down at bottom and later experimental animals were placed into chambers. The animals were kept for 10 min in deadly gas and finally animals got dead due to failure of central nervous system ${ }^{[29]}$. The rate of inhibition (\%) was determined as follows, inhibition rate $(\%)=($ average PCV of control-average PCV of treated)/average PCV of control.

\section{Cytotoxicity assay:}

The cytotoxicity of test samples was evaluated on cloned Chinese hamster V79 cells $^{[28]}$. These experimental 
cells were obtained from JFCR, Japan and cultured on RPMI 1640 culture medium. The culture medium was supplemented with fetal calf serum $(10 \%)$ and kanamycin $(1000 \mu \mathrm{g} / \mathrm{ml})$. Chinese hamster V79 cells $\left(3 \times 10^{5}\right.$ cells/well $)$ were transferred in six wells plates. The each plate was poured with $2 \mathrm{ml}$ growth culture medium and incubated at $30^{\circ}$ in humid atmospheric condition $\left(5 \% \mathrm{CO}_{2}\right)$. The test samples were $(10 \mu \mathrm{l})$ added to the culture wells on day 1 of transplantation. Later, the colonies of Chinese hamster V79 cells were fixed with formaldehyde solution $(2.0 \mathrm{ml})$. On $5^{\text {th }} \mathrm{d}$, the developed colonies were stained with $0.05 \%$ crystal violet $(0.75 \mathrm{ml})$. The cytotoxic assay of test samples was calculated by recording the number of stained colonies of test group/colonies of control group $\times 100$.

\section{Statistical analysis:}

The experimental data were expressed as mean, standard deviation (SD) and statistically assessed by one analysis of variance (ANOVA). The inhibition rate (\%) of antioxidant, antineoplastic and cytotoxic activities of test samples are reported as mean $\pm \mathrm{SD}$. $\mathrm{P}<0.05$ was considered as statistically significant.<smiles>COc1c(-c2ccccc2)oc2cc(O)cc(O)c2c1=O</smiles>

A<smiles>O=c1cc(-c2ccccc2)oc2cc(O)cc(O)c12</smiles>

\section{RESULTS AND DISCUSSION}

The flavonoids are very large class of phytochemicals, widely occur in plants and perform various significant roles. The flavonoids possess antimicrobial, antioxidant, and antiinflammatory activities. The dichloromethane crude fraction was analyzed phytochemically and five flavonoids were characterized viz., 3-O-methylgalangin (217 mg), naringenin-4, 7-dimethyl ether (427 mg), chrysin (372 mg), luteolin (324 mg), sakuranetin (276 mg; fig. 1). The isolated flavonoids were tested for their antioxidant, antineoplastic and cytotoxic activities.

For the screening of antioxidant activity of isolated compounds, the four assay models were used. The DPPH assay is widely accepted by the researchers for the assessment of antioxidant activity. For the determination of antioxidant activity, several concentrations $(10,20,30,50,75$ and $100 \mu \mathrm{M})$ of test samples were used. It was found that maximum DPPH scavenging activity demonstrated by the chrysin $(297.21 \pm 0.36 \%)$ at dose of $30 \mu \mathrm{M}$. Along with crysin, the other flavonoid as luteolin $(278.33 \pm 0.19 \%)$<smiles>COc1ccc(-c2cc(=O)c3ccc(OC)cc3o2)cc1</smiles>

B<smiles>O=c1cc(-c2ccc(O)c(O)c2)oc2cc(O)cc(O)c12</smiles>

D<smiles>COc1cc(O)c2c(=O)cc(-c3ccc(O)cc3)oc2c1</smiles>

Fig. 1: Structures of isolated flavonoids from resinous exudate of $\boldsymbol{H}$. ellipticum A: 3-O-methylgalangin, B: naringenin-4, 7-dimethyl ether, C: chrysin, D: luteolin, E: sakuranetin 
also exhibited significant scavenging effects to free radicals. Similarly, the dichloromethane fraction showed minimum scavenging effects $(127.55 \pm 0.32 \%)$ at $100 \mu \mathrm{M}$ dose (fig. 2). The DPPH scavenging assay of isolated flavonoids was compared with the ascorbic acid (standard drug) and found that chrysin was more potent radical scavenger than the ascorbic acid (212.45 $\pm 0.28 \%$; fig. 2).

The reducing power potential of test samples was analyzed by potassium ferric cyanide reduction. As per observed results, the test samples reduced the ferric complex to ferrous complex by electron donation. The test sample's absorbance was measured at $700 \mathrm{~nm}$ and the higher reducing potentiality judged by increase in absorbance. Chrysin showed strongest reducing power activity $(428.21 \pm 0.23 \%)$ at $30 \mu \mathrm{M}$ dose while dichloromethane fraction demonstrated minimum activity $(178.37 \pm 0.62 \%)$ at $50 \mu \mathrm{M}$ dose. The moderate reducing power potency $(398.23 \pm 0.33 \%)$ was showed by luteolin as also compared with ascorbic acid (351.14 $\pm 0.43 \%$; fig. 2).

Superoxide anion radicals are quite toxic and used to kill invading pathogens by immune system. The radicals are considered as precursors to DNA damage and cause several types of diseases. In phagocytes, these radicals are produced in large quantities by NADH oxidase to kill the pathogens. Superoxide anion scavenging activity of test samples was assessed by NBT reduction method. The decrease in absorbance by antioxidants indicated the utilization of superoxide anion radicals in the reaction mixture. Maximum superoxide radical scavenging effects was showed by chrysin $(283.59 \pm 0.39 \%) 30 \mu \mathrm{M}$ dose and lowest by dichloromethane fraction $(157.34 \pm 0.85 \%)$ at $50 \mu \mathrm{M}$ dose. The moderate level of activity was demonstrated by luteolin (256.74 $\pm 0.14 \%$ ) at $30 \mu \mathrm{M}$ dose (fig. 2).

The main strategy of metal chelating activity is to stop the formation of ROS metal ion complexes. Among isolated flavonoids, the strong chelator checks the production of ferrous-ferrozine complex. In our study, maximum metal chelating activity was showed by the chrysin $(459.52 \pm 0.11 \%)$ at $30 \mu \mathrm{M}$ dose and minimum by dichloromethane fraction $(243.56 \pm 0.41 \%)$ at $50 \mu \mathrm{M}$ dose. Similarly, the other isolated flavonoids including as luteolin exhibited moderate metal chelating potentiality $(428.16 \pm 0.32 \%)$ at $30 \mu \mathrm{M}$ dose (fig. 2). On comparison of activity with ascorbic acid $(429.54 \pm 0.55 \%)$, it was found that chrysin showed strongest metal chelating activity. The change of color of test solution during experimental study indicated the strong ability of isolated flavonoids against metal chelation.

Plant-derived active principles are considered as potent anticancer agents with no negative effects on human health as well as they are more economical also. The antineoplastic activity was assessed by PCV method. The test samples were tested for their antineoplastic activity and found that chrysin demonstrated maximum inhibition $(81.90 \pm 0.28 \%)$ against Sarcoma 180 when compared with the animals of control group at $20 \mu \mathrm{g} / \mathrm{kg} / \mathrm{d}$ dose. Luteolin $(79.04 \pm 0.28 \%)$ and other

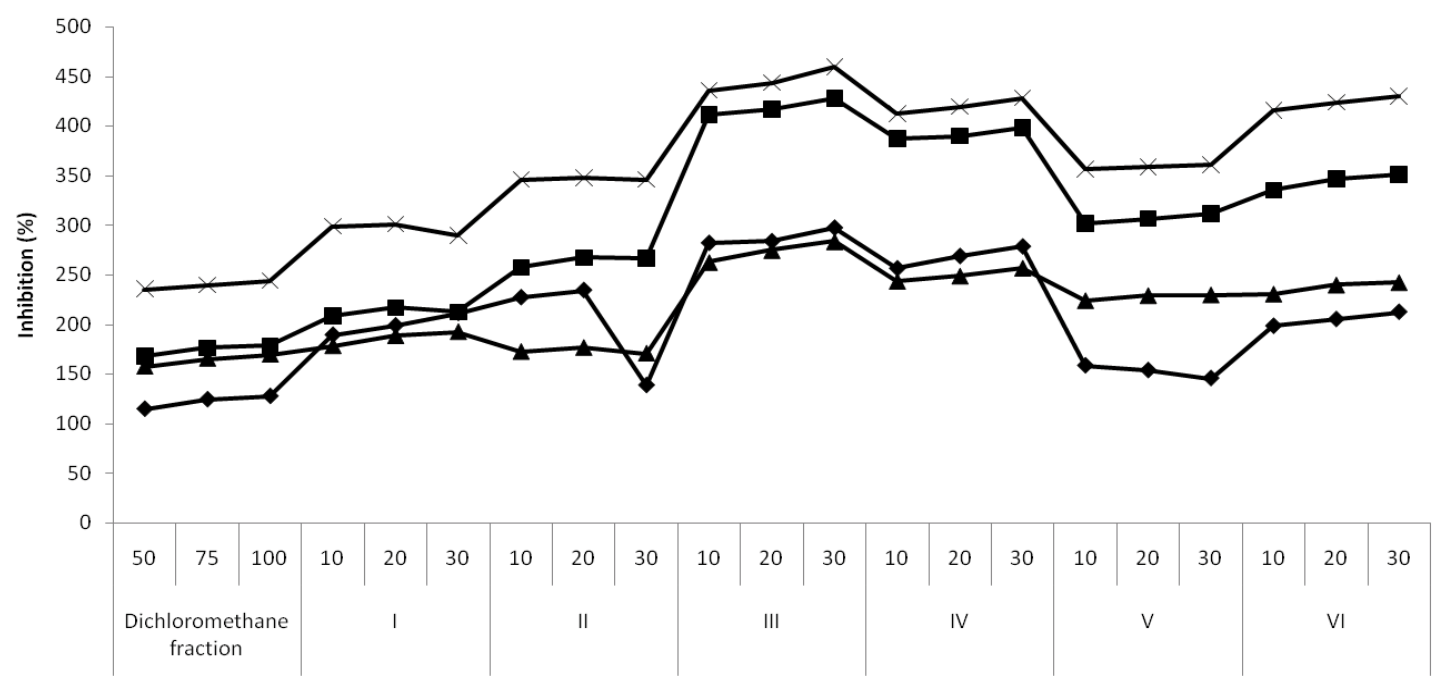

Fig. 2: In vitro antioxidant activity of dichloromethane fraction and isolated flavonoids from $\mathrm{H}$. ellipticum

- - DPPH- radical scavenging (\%); - - - reducing power (\%); - $\Delta$ - superoxide anion scavenging (\%); - $x$ - metal chelating scavenging (\%). The three concentrations of dichloromethane fraction $(50,75$ and $100 \mu M)$ and isolated compounds $(10,20$ and $30 \mu M)$ were tested in this study. The inhibition rate (\%) of antioxidant activities of test samples are reported as mean \pm SD. $\mathrm{P}<0.05$ was considered as statistically significant 
isolated flavonoids also showed their potential to check the growth of Sarcoma 180 at different levels of inhibition (fig. 3). For the determination of cytotoxic activity, the Chinese hamster V79 cells were used and the test samples were tested with 1.0 to $100 \mu \mathrm{g} / \mathrm{ml}$ concentration. Strongest cytotoxic activity was showed by chrysin $(37.2 \pm 0.67 \%)$ with $90 \mu \mathrm{g} / \mathrm{ml}$ concentration while moderate activity was exhibited by luteolin $(39.4 \pm 0.45 \%)$ at $100 \mu \mathrm{g} / \mathrm{ml}$. Similarly, the other isolated test samples were also active against Chinese hamster V79 cells at different concentrations (fig. 4).

Flavonoids have abilities to scavenge the free radicals because they stimulate the activity of glutathioneS-transferase, the enzyme ensures the safety of cells

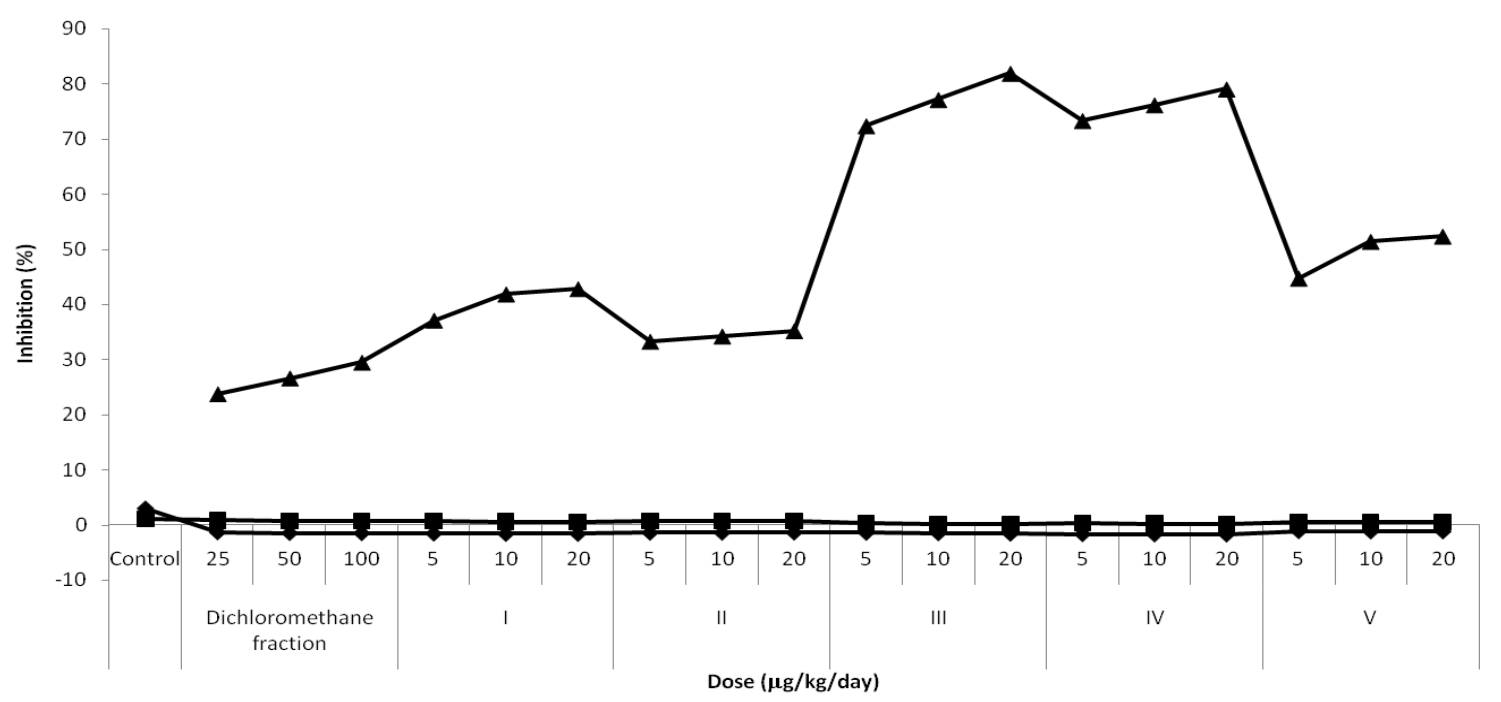

Fig. 3: In vivo Antineoplastic activity of active fraction and isolated flavonoids from $H$. ellipticum against Sarcoma 180 -४- BWC1; -m- PCV2 T/C; - $\triangle$ - inhibition ${ }^{3}(\%)$. The three doses of dichloromethane fraction $(25,50$ and $100 \mu \mathrm{g} / \mathrm{kg} / \mathrm{d}) \mathrm{and}$ isolated compounds $(5,10$ and $20 \mu \mathrm{g} / \mathrm{kg} / \mathrm{d})$ were tested in this study. The experimental animals were divided into seven groups (control, dichloromethane fraction and five isolated compounds). The body weight was reduced in treated groups of animals while increased in the animals of control group. The inhibition rate (\%) of antineoplastic activity of test samples are reported as mean \pm SD. $\mathrm{P}<0.05$ was considered as statistically significant

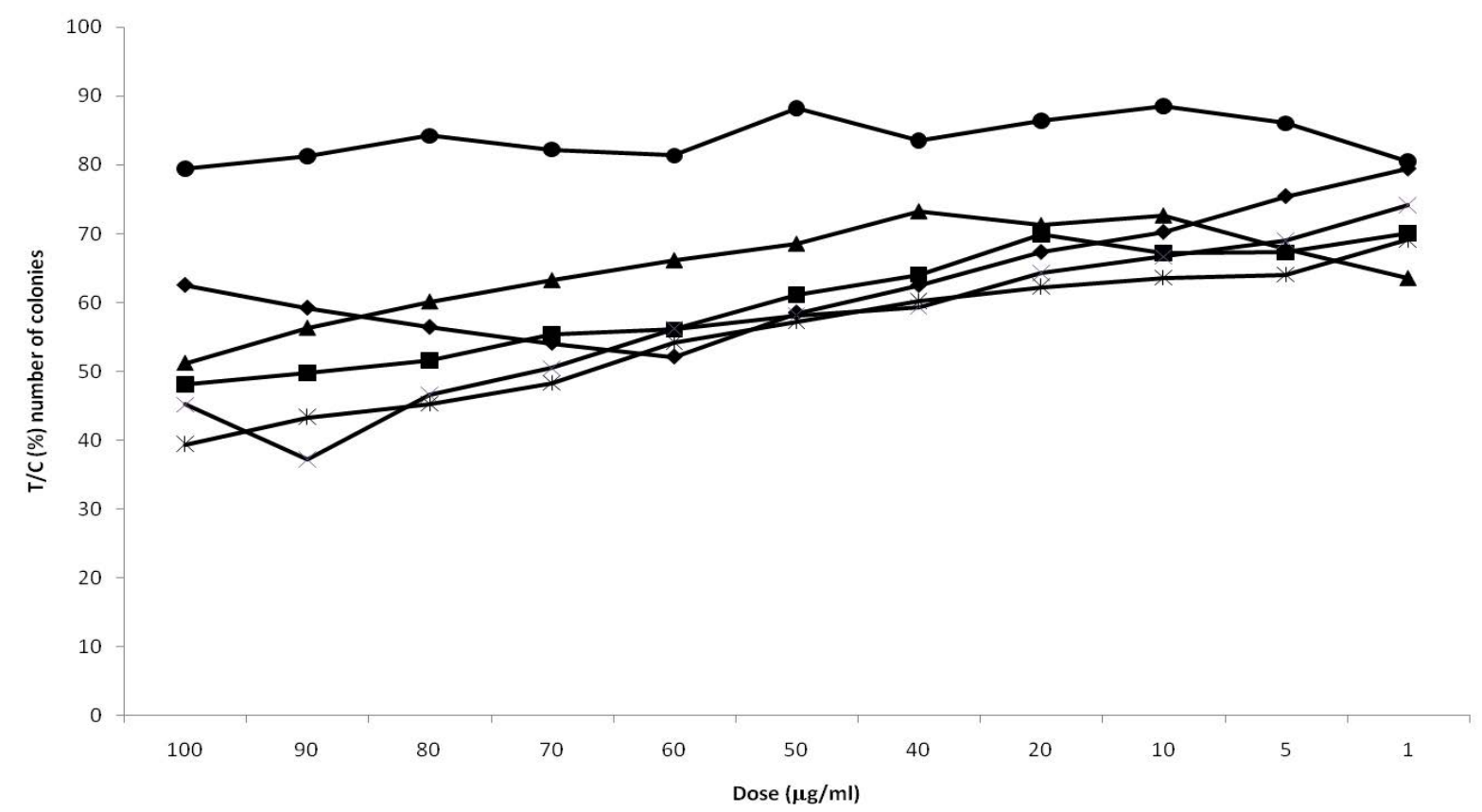

Fig. 4: In vitro cytotoxic activity of active fraction and isolated flavonoids from $\mathrm{H}$. ellipticum against Chinese hamster V79 cells

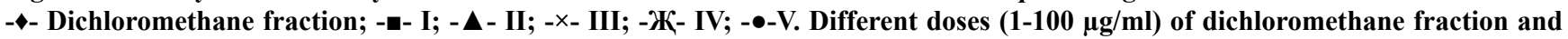
isolated compounds were tested in this study. The cytotoxic assay of test samples was calculated by recording the number of stained colonies of test group/colonies of control group $\times 100$. The inhibition rate (\%) of cytotoxic activity of test samples are reported as mean \pm SD. $P<0.05$ was considered as statistically significant 
damaged by free radicals ${ }^{[30]}$. The antioxidant property of flavonoids is totally dependent on their chemical configurations. The flavonoids are having orthohydroxy group in B-ring as well as carbonyl group at C-4 (C-ring $)^{[31]}$. The DPPH radical scavenging assay is a widely accepted method used to evaluate the potency of flavonoids to scavenge free radicals ${ }^{[32]}$. Chrysin that has 3'4'-dihydroxyl groups showed greater scavenging activity to DPPH free radicals. Due to the presence of dihydroxyl groups, the quercetin possessed strong DPPH scavenging activity ${ }^{[33]}$. The ortho-hydroxy structure in the B-ring and the 2, 3-double bond in conjugation with the 4-oxo function of the C-ring showed promising antioxidant capacity of luteolin ${ }^{[34]}$. As per our results, the luteolin and other isolated flavonoids also demonstrated significant scavenging potency to the DPPH free radicals.

In case of reducing power assay, the antioxidant compounds reduce $\mathrm{Fe}^{3+} /$ ferricyanide complex to ferrous form due to their reduction capabilities. During the course of study, we observed that the chrysin was most effective reducing agent among other isolated flavonoids. The reducing power ability of compounds is attributed to the breakdown of the free radical chain $^{[35]}$. Our results are in agreement with the results of Nandini et al. ${ }^{[36]}$. It was also observed that all the investigated compounds demonstrated concentration dependent activity but activity varied as per the studied model systems ${ }^{[37]}$.

Superoxide anion radicals are formed by reduction of molecular oxygen as well as leakage of electrons from electron transport chain. Superoxide anion radicals protect our body from the bacterial pathogens and excessive radicals removed by the superoxide dismutase $^{[38]}$. Due to the presence of hydroxyl groups in B-ring as well as presence of carbonyl group on $\mathrm{C}$-ring in structure of chrysin demonstrated maximum superoxide anion scavenging activity and the results are in agreement with study of Hubbe and Joubert ${ }^{[39]}$.

The metal chelating activity of compounds depends on the ability of compounds to reduce redox potential and the stabilization of oxidized state of metals. The active compounds stop the generation of metal hydroperoxide complex ${ }^{[40]}$. The presence of hydroxyl groups at $\mathrm{C}-3$ positions in flavones responsible for the promising metal chelating activity ${ }^{[41]}$. This metal chelating activity of chrysin against oxidative stress is expressed by increasing the enzymatic and nonenzymatic activities and by reducing the intensity of lipid peroxidation. Quercetin and luteolin were also considered as valuable metal chelator compounds ${ }^{[42]}$.

Chemotherapy is a significant strategy to control cancer in humans ${ }^{[43]}$. It is essential that these chemotherapeutic agents must be nontoxic, active, and available at low $\operatorname{cost}^{[44]}$. The significant role of 3'-hydroxyl group was established when the antiproliferative activity of naringenin and eriodictyol compared together. The only structural difference in both flavonoids is the presence of a 3-hydroxyl group in the eriodictyol molecule, which increases the anticancer and cytotoxic effects. At $20 \mu \mathrm{g} / \mathrm{kg} / \mathrm{d}$ dose, chrysin was more active against sarcoma 180 than other concentrations tested. Some investigators have suggested that the growth inhibition activity of polymethoxylated flavonoids may, in part, be attributed due to their chemical stability ${ }^{[45]}$. At the concentration of $90 \mu \mathrm{g} / \mathrm{ml}$, chrysin inhibited colony formation of Chinese hamster V79 cells more effectively than luteolin. The luteolin was able to check the growth of the H292 cancer cells ${ }^{[46]}$. Results indicated that chrysin with a hydroxyl group in B-ring, is more potent antineoplastic and cytotoxic agent at different tested concentrations. It was also observed that other isolated flavonoids showed weaker to moderate activities. Luteolin and quercetin have shown a significant cytotoxicity against HEPG2 liver cell lines and gastric cancer cells at dose dependent manner. The cytotoxicity of luteolin was equal to vincristine $^{[47,48]}$.

Several new synthetic compounds synthesized in recent years failed to be better alternatives to secondary metabolites of plants ${ }^{[49]}$. Polyphenols are important secondary products synthesized by plants through various metabolic pathways and these possess redox potential. Due to their redox abilities, the polyphenolic compounds are considered as potent reducing agents and hydrogen donators. Chrysin isolated from the dichloromethane fraction of $H$. ellipticum exhibited strong antioxidant activity by scavenging DPPH radicals.

Flavonoids could be effective anticancer agents through inhibition of various stages of the carcinogenesis process. These compounds have different mechanism of actions including apoptosis induction, antiproliferation and others. Owing to these mechanisms, flavonoids might act as useful anticancer agents. Expectedly, chrysin demonstrated promising antineoplastic and cytotoxic effects against selected experimental models. Though, the isolated flavonoids from $H$. ellipticum 
demonstrated significant antioxidant, antineoplastic and cytotoxic activities, further studies are needed to elucidate the exact mechanism of action to develop those as potent antioxidant and anticancer agents.

\section{Acknowledgements:}

Authors thank Professor R. S. Mishra, Department of Botany, University of Rajasthan, Jaipur, India for authenticating the plant. Authors are also grateful to Professor P. Singh, Department of Chemistry, University of Rajasthan, Jaipur for providing standard compounds, Professor Dr. H. Itokawa, College of Pharmacy, Tokyo, for his kind help in the screening process of antineoplastic and cytotoxic activities and Dr. Tsukagoshi, JFCR, Japan for providing Chinese hamster V79 cells.

\section{Conflict of interest:}

The authors wish to declare that there are no conflicts of interest associated with this research work and similarly there has been no financial support involved in this work that could affect its outcome.

\section{Financial support and sponsorship:}

Nil.

\section{REFERENCES}

1. Dell B, Comb J. Plants resins, their function, secretion and possible function. Adv Bot Res 1979;6:277-316.

2. Chopra RN, Nayar SL, Chopra IC. Glossary of Indian medicinal plants. New Delhi: CSIR; 1956.

3. Singh G, Kachroo P. Forest Flora of Srinagar and Plants of Neighbourhood. Dehradun: Bishen Singh Mahendra Pal Singh; 1976.

4. Kirtikar KR, Basu BD. Indian medicinal plants. Mumbai: Popular Book Depot; 1967.

5. Modak B, Rojas M, Torres R. Chemical analysis of the resinous exudate isolated from Heliotropium taltalense and evaluation of the antioxidant activity of the phenolics components and the resin in homogenous and heterogenous systems. Molecules 2009;14:1980-9.

6. Modak B, Sandino A, Arata L, Cardenas JG, Torres R. Inhibitory effect of aromatic geranyl derivatives isolated from Heliotropium filifolium on infectious pancreatic necrosis virus replication. Vet Microbiol 2010;141:53-8.

7. Singh B, Sharma RA. Anti-inflammatory and antimicrobial properties of flavonoids from Heliotropium subulatum exudates. Inflamm Allergy Drug Targets 2015;14:125-32.

8. Singh B, Sharma RA. Anti-inflammatory and antimicrobial properties of flavonoids from Heliotropium ellipticum exudate. Curr Bioactive Compounds 2016;12:123-31.

9. Lü JM, Lin PH, Yao Q, Chen C. Chemical and molecular mechanisms of antioxidants: experimental approaches and model systems. J Cell Mol Med 2010;14:840-60.
10. Yildrim A, Mavi A, Oktay M, Kara AA, Algur OF, Bilaloglu V. Comparison of antioxidant and antimicrobial activities of tilia (Tilia arentea Desf Ex DC), sage (Salvia triloba L), and black tea (Camellia sinenesis L) extracts. J Agric Food Chem 2000;48:5030-4.

11. Duh PD, Du PC, Yen GC. Action of methanolic extract of mung bean hulls as inhibitors of lipid peroxidation and nonlipid oxidative damage. Food Chem Toxicol 1999;37:1055-61.

12. Halliwell B, Gutteridge JMC. Oxygen toxicity, oxygen radicals, transition metals and disease. Biochem $\mathrm{J}$ 1984;219:1-14.

13. Karamać M. Chelation of $\mathrm{Cu}$ (II), $\mathrm{Zn}$ (II), and Fe (II) by tannin constituents of selected edible nuts. Int J Mol Sci 2009;10:5485-97.

14. Sarmadi BH, Ismail A. Antioxidant peptides from food proteins: a review. Peptides 2010;31:1949-56.

15. Batra P, Sharma AK. Anticancer potential of flavonoids: recent trends and future perspectives. 3 Biotech 2013;3:439-59.

16. Shaked Y, Emmenegger U, Francia G, Chen L, Lee CR. Low dose metromonic combined with intermittent bolus-dose cyclophosphamide is an effective long-term chemotherapy treatment strategy. Cancer Res 2005;65:7045-51.

17. Treasure T, Followfield L, Farewell V, Ferry D, Lees B, Leonard P. Pulmonary metastasectomy in colorectal cancer: time for a trial. Eur J Surg Oncol 2009;35:686-9.

18. da Silva SAS, Agra MF, Tavares JF, da Cunha EVL, BarbosaFilho JM, da Silva MS. Flavanones from aerial parts of Cordia globosa (Jacq.) Kunth, Boraginaceae. Brazilian J Pharmacog 2010;20:682-5.

19. Zhang H, Xu LX, Wu P, Wei XY. Flavonoids from the aerial parts of Alpinia officinarum. J Trop Subtrop Bot 2014;22:89-92.

20. Özgen U, Mavi A, Terzi Z, Kazaz C, Aşçi A, Kaya Y, et al. Relationship between chemical structure and antioxidant activity of luteolin and its glycosides isolated from Thymus sipyleus subsp. sipyleus var. sipyleus. Rec Nat Prod 2011;5:12-21.

21. Wollenweber E, Wehde R, Dörr M, Stevens JF. On the occurrence of exudate flavonoids in the borage family (Boraginaceae). Z Naturforsch C 2002;57c:445-8.

22. Zhang X, Guo P, Sun G, Chen S, Yang M, Fu N, et al. Phenolic compounds and flavonoids from the fruits of Pandanus tectorius Soland. J Med Plants Res 2012; 6:2622-6.

23. Yokozawa T, Chen CP, Dong E, Tanaka T, Nonaka GL, Nishioka I. Study on the inhibitory effect of tannins, flavonoids against the 1,1- diphenyl-2-pycylhydrazyl radical. Biochem Pharmacol 1998;56:213-22.

24. Shimada K, Fujikawa K, Yahata K, Nakamura T. Antioxidative properties of xanthan on oxidation of soybean oil in cyclodextrin emulsion. J Agric Food Chem 1992;40:945-8.

25. Robak J, Gryglewski RJ. Flavonoids are scavengers of superoxide anions. Biochem Pharmacol 1998;37:837-41.

26. Dinis TCP, Medeira VMC, Almeida MLM. Action of phenolic derivates (acetoaminophen, salicylate, and 5-aminosalicylate) as inhibitors of membrane lipid peroxidation and as a peroxyl radical scavengers. Arch Biochem Biophys 1994;315:161-9.

27. Blom HJM, Van Tintelen G, Van Vorstenbosch CJAHV, Baumans V, Beynen AC. Preference of mice and rats for types of bedding material. Lab Anim 1996;30:234-44.

28. Itokawa $\mathrm{H}$, Watanabe $\mathrm{K}$, Mihashi S. Screening test for 
antitumor activity of crude drugs. Shoyakugaku Zasshi 1979;33:95-8.

29. Nolen RS. Revision process begins for AVMA euthanasia guidelines. J Am Vet Med Assoc 2009;235:246-7.

30. Fiander H, Schneider H. Dietary ortho phenols that induce glutathione-S-transferase and increase the resistance of cells to hydrogen peroxide are potential cancer chemopreventives that act by two mechanisms: the alleviation of oxidative stress and the detoxification of mutagenic xenobiotics. Cancer Lett 2000;156:117-24.

31. Grael CFF, Kanashiro A, Kabeya LM, Jordáo CO, Takeara R, Gobbo-Neto L, et al. In vitro study of antioxidant and scavenger properties of phenolic compounds from Lychnophora species. Química Nova 2010;33:867-70.

32. Kutlu T, Durmaz G, Ateş B, Yilmaz I, Çetin MŞ. Antioxidant properties of different extracts of black mulberry (Morus nigra L). Turkish J Biol 2011;35:103-10.

33. Furusawa M, Tanaka T, Ito T, Nishikawa A, Yamazaki N, Tsuchiya $\mathrm{H}$, et al. Antioxidant activity of hydroflavonoids. J Health Sci 2005;51:376-8.

34. Campos AM, Lissi E, Chavez M, Modak B. Antioxidant activity in heterogeneous and homogeneeous system of the resinous exudates from Heliotropium stenophyllum and $H$. sinuatum and of 3-O-methyl galangin their main component. Bol Latinoam Caribe Plant Med Aromat 2012;11:549-55.

35. Koleva II, van Beek TA, Linssen JPH, De Groot A, Evstatieva LN. Screening of plant extracts for antioxidant activity, a comparative study on three testing methods. Phytochem Anal 2002;13:8-17.

36. Nandini S, Suchetha Kumar N, Ramesh CK, Aditya Rao SJ. The in vitro antioxidant activity and total phenolic content of flavonoid luteolin and Tamarindus indica pod extract and its methanol fraction. World J Pharm Pharm Sci 2015;4:1008-16.

37. Materska M. Flavone C-glycosides from Capsicum annuum L: relationships between antioxidant activity and lipophilicity. Eur Food Res Technol 2015;240:549-57.

38. Packer L, Glazer AN. Methods in enzymology: oxygen radicals and antioxidants. Vol 186. San Diego: Academic Press; 1990.
39. Hubbe ME, Joubert E. In vitro superoxide anion radical scavenging ability of honeybush tea (Cyclopia). In: Johnson IT, Fenwick GR, editors. Dietary anticarcinogens and antimutagen: chemical and biological aspects. Cambridge: Royal Society of Chemistry; 2000. p. 242-44.

40. Končić MZ, Barbarić M, Perkovic I, Zorc B. Antiradical, chelating and antioxidant activities of hydroxamic acids and hydroxyureas. Molecules 2011;16:6232-42.

41. Malešev D, Kuntić V. Investigation of metal-flavonoid chelates and the determination of flavonoids via metal flavonoid complexing reactions. J Serb Chem Soc 2007;72:921-39.

42. Seelinger G, Merfort I, Wölfle U, Schempp CM. Anticarcinogenic effects of the flavonoid luteolin. Molecules 2008;13:2628-51.

43. Hong WK, Sporn MB. Recent advances in chemoprevention of cancer. Science 1997;278:1073-7.

44. Ruhul Amin ARM, Kucuk O, Khuri FR, Shin DM. Perspectives for cancer prevention with natural compounds. J Clin Oncol 2009;27:2712-25.

45. Kandaswami C, Perkins E, Soloniuk DS, Drzewiecki G, Middleton E. Ascorbic acid-enhanced antiproliferative effect of flavonoids on squamous cell carcinoma in vitro. Anticancer Drugs 1993;4:91-6.

46. Majumdar D, Jung KH, Zhang H, Nannapaneni S, Wang $\mathrm{X}$, Ruhul Amin ARM, et al. Luteolin nanoparticle in chemoprevention - in vitro and in vivo anticancer activity. Cancer Prev Res (Phila) 2014;7:65-73.

47. Yoshida M, Sakai T, Hosokawa N, Marui N, Matsumoto $\mathrm{K}$, Fujioka A, et al. The effect of quercetin on cell cycle progression and growth of human gastric cancer cells. FEBS Lett 1990:260:10-3.

48. Hanchinalmath JV, Londonkar R. Cytotoxic and apoptosisinducing effect of luteolin isolated from Feronia limonia on HEPG2 cells. Biolife J 2014;2:1287-9.

49. Al-Rashidi W, Supri NNM, Mansoor N. Cytotoxic activities of crude extract from Costus malortieanus (Costaceae). AmEuras J Toxicol Sci 2011;3:63-6. 